\title{
Methodical approaches to the application of new technologies in the innovative resource- saving system
}

\author{
Oleg Andreev ${ }^{1, *}$ \\ ${ }^{1}$ Samara State Economic University, 443090, 141 Sovetskoi Armii str., Samara, Russia
}

\begin{abstract}
The urgency of the problem being investigated is conditioned by the issues of rational use of natural resources in the conditions of transition of the economy to the trajectory of sustainable development. The analysis of conceptual views on this issue points to many arguments, which indicates a divergence of theoretical positions. The purpose of the article is aimed at the formation of a resource-saving strategy and the concepts of "cleaner production", which are one of the decisive ways in increasing the efficiency of the use of natural resources. In recent years, this process is significantly intensified, which is associated with the extraction, processing and transportation of oil and gas, which are a dangerous source of possible environmental complications. The manifestation of increased attention to the problem being investigated is based on an understanding of the main role of resource saving in market conditions. The leading approach to the study of this problem was the structural reorganization of existing production facilities and the creation of new ones based on the integrated use of petroleum raw materials, taking into account the introduction of innovative processes. The main components of scientific novelty are directions that have been further developed and containing elements of a real increase in scientific knowledge. The main results of the article are aimed at justifying the development of all components of resource-saving links. The materials of the article can be used to improve the state policy in the field of resource saving, using the principles and tools of the "cleaner production" concept, as well as in teaching courses in economic theory, the theory of resource-saving management.
\end{abstract}

\section{Introduction}

The globalization of the world economy is accompanied by an excessive man-caused strain on the natural environment, which causes not only the degradation of local ecosystems, but also the cause of accelerating global climate change. The increase in natural natural anomalies causes great economic damage to national economies. In this connection, the theory of economic efficiency requires further development.

\footnotetext{
* Corresponding author: prekrasnova.v@ mail.ru
} 
It is legitimate to talk about the appearance of the fourth factor of production - the ability of the natural environment to take pollutants, while not changing its quality parameters. Consideration for the environmental factor of production in the indicators of the financial performance of enterprises is quite a difficult task, which is based on the problem of the economic valuation of natural goods [2].

Until the 80 s of the last century, man viewed nature as the source of "objects of labor." The economic evaluation of natural goods was limited to determining the value of certain natural resources. In connection with the aggravation of local, regional and global environmental problems, there is a need to economically assess other popular functions of nature: the assimilation potential of ecosystems, natural services (recreational, aesthetic, etc.).

K. Marx revealed the nature of the three main factors of production: the object of labor, the means of labor and labor itself, which are amenable to valuation and are taken into account in calculating the economic efficiency of production.

The concept of eco-efficiency is one of the driving forces that guides modern business towards sustainable development.

WBCSD to enhance the eco-efficiency of the global economy has proposed two strategic orientations:

- "Factor 10": the application of technologies that will reduce the negative impact on the environment 10 times while maintaining the existing volume of production;

- "Factor 4": fourfold increase in the productivity of natural resources due to a twofold increase in profits and a twofold reduction in the consumption of resources, and hence, the burden on the environment.

Theoretical foundations of the concepts of Cleaner Production and Eco-efficiency are very similar in many aspects.

The concept of "Eco-efficiency" and tools for its implementation are developed for countries that have achieved great success in solving economic and social problems.

These countries have effective environmental legislation, there are high taxes on environmental pollution, as a rule, high prices for imported raw materials, which in general creates good prerequisites for the development of programs aimed at improving environmental efficiency.

Moreover, these countries in the $80 \mathrm{~s}$ were characterized by capital-intensive environmental technologies associated, as a rule, with the installation of expensive treatment facilities, which adversely affected the competitiveness of products.

The term "eco-efficiency" refers to the practice of companies that closely interrelate economic and environmental efficiency.

Eco-efficiency means efficiency of resource-saving and is characterized by such indicators as resource efficiency and effectiveness of environmental protection measures.

Eco-efficiency of the enterprise is characterized by a system of indicators of ecoefficiency.

Indicators of eco-efficiency are the ratio of indicators of economic (financial) and environmental performance of the enterprise, for example, energy consumption (ton of reference fuel or $\mathrm{kWh}$ ) to the volume of output (in monetary units); the mass of construction waste (in tons) to the number of turnkey apartments; profit (in monetary units) to greenhouse gas emissions (in tonnes of $\mathrm{CO} 2$ equivalent), etc.

The value of indicators of eco-efficiency consists in the possibility of comparing them with each other.

Indicators of eco-efficiency allow companies to compare with similar indicators of competitors and with the average performance of the industry as a whole [3].

"High eco-efficiency" indicates a higher investment attractiveness of the organization, leading to an increase in the value of the company's shares. 
Eco-efficiency indicators can be grouped into three main groups.

I: The ratio of the two environmental components to each other in natural units of mass or volume. For example, the amount of waste (in tonnes) / total consumption of resources for production (in tonnes).

II: The ratio of environmental performance in terms of mass or volume and financial performance in monetary units. For example, the volume of $\mathrm{CO} 2$ emissions (in tons) / sales (in monetary units), net profit / total water consumption (in tonnes).

III: The ratio of environmental performance, expressed in monetary units and financial performance of the enterprise. For example, profit / charge for energy consumption.

The WBCSD identifies two types of environmental performance indicators:

- Generally applicable (generic);

- Sector specific.

Commonly applicable indicators allow you to compare everything without excluding the enterprise, regardless of the type of production activity and geographic situation.

Specific sectoral indicators reflect a specific (sector-specific) impact of a particular industry on the environment.

To determine the set of priority generally applicable (standard) indicators of environmental performance and their assessment, it is first necessary to select the most significant environmental problems.

So, Kaspar Mueller and Dr. Andreas Sturm [8] recommend recognizing as the most significant environmental problems:

- Depletion of non-renewable energy resources;

- Depletion of fresh water resources;

- Global warming;

- Depletion of the ozone layer;

- Placement of solid and liquid (including hazardous) wastes.

The WBCSD proposes that when assessing the contribution of enterprises to global problems, the following priorities should be guided:

- Total energy consumption;

- Consumption of material resources;

- Water consumption;

- Emissions of greenhouse gases into the atmosphere;

- Emissions of gases that deplete the ozone layer.

Further, the WBCSD proposes to evaluate the participation of the enterprise in solving or exacerbating one or another environmental problem.

Consider the indicator of eco-efficiency, corresponding to the problem of rational use of water.

The consumption of water is measured in cubic meters.

In this case, it is necessary to take into account various branch features:

- The nature of the use of water,

- The degree of contamination of sewage,

- Reuse of water, etc.

A significant role is played by the geographic position of the enterprise, since water resources are distributed on the Earth's surface with extremely uneven.

To compare objectively enterprises of one industry located in different climatic zones by the level of water consumption, correction factors should be used, taking into account climatic conditions, the degree of man-caused pollution of the environment, etc.

In developing countries, the environmental costs of polluting enterprises, including payments for pollution and fines for violations of environmental legislation, are inadequate to the damage to the environment. 
As a rule, prices for electricity and raw materials are low, in addition, environmental legislation and mechanisms for suppressing violations are not perfect.

Initially, great progress at low costs can be achieved in industries where resources have traditionally been used inefficiently, but low prices for raw materials and natural resources will hinder further eco-efficiency improvements.

Implementation of measures to prevent pollution in the presence of cheap natural resources in our opinion will require the adoption of strict laws, legal norms, environmental and technical standards.

At the same time, real support from the state (educational, information and organizational) is important in the problem of improving eco-efficiency [4].

At low prices for energy and other raw materials, the prospect of applying the concept of eco-efficiency will largely depend on the tax policy of the state.

Today, taxes are subject to labor and capital.

The WBCSD recommends that emphasis be placed on the consumption of natural resources and environmental pollution, which will force enterprises to focus on reducing the material and energy intensity of production, which in turn will reduce the harmful impact on the environment and improve the indicator of "true savings".

It should be noted that the principle of economic efficiency is a universal principle, guided at all levels.

The question arises: how are "a continuous application" and "a systematic approach" actually implemented?

The concept of Cleaner Production was based on the concept of continuous technological changes, more commonly known now as the Deming cycle.

It is believed that, thanks to the universality of the 14 principles of Deming's quality management theory, Japan made rapid progress in the development of industry in its time.

It is necessary to consider the following benefits (the payback period of the required investments, the reduction of the resource intensity of products and the increase of its competitiveness in the market, the further increase in profits, the possibility of improving the quality of products, improving the company's ecological image, etc.).

Ecological and economic efficiency of the functioning of the enterprise essentially depends on the type of resource-saving.

As practice shows, not always the most capital-intensive measures are effective from the point of view of achieving environmental goals and increasing the economic efficiency of the enterprise.

Enterprises are given a greater degree of freedom in choosing production strategies.

Enterprises can choose different ways to reduce production waste, among which are the following:

1) replacement of raw materials, energy carriers and explosives used in the technological process (for example, open-pit coal mining) to environmentally cleaner analogs, which (replacement) will lead to the formation of less polluting (including toxic and radioactive) substances;

2) replacement of used gas and water treatment plants with better analogues (by the cleaning factor);

3) improved processing of raw materials used, which reduces the specific resource consumption of products and reduces the formation of waste per unit of production;

4) utilization of industrial waste, which leads to the receipt of additional products, the implementation of which can significantly improve the financial performance of the enterprise;

5) recultivation of disturbed lands, purification of natural reservoirs, planting of forest tracts and other [7].

In solving environmental problems, a special role is always assigned to the state. 
This is because the market can not solve the problems of externalities without the mediation of the state. Negative ecological externalities arise when some economic subjects excessively consume a limited natural resource (for example, the assimilation capacity of the ecosystem), which causes other subjects of the same economic system to incur additional costs to satisfy their needs in the same resource.

Coase's theorem states that "whenever externalities arise, stakeholders can come together and work out agreements according to which externalities from external effects are transformed into internal factors, and efficiency is provided" [7].

J. Stiglitz notes that, despite Coase's statement (Coase's theorem), there is always a problem of "rabbits". Not all "victims" of external externalities take an active position to avoid transaction costs.

To develop a resource management system, it is necessary to use economic instruments and mechanisms.

The active use of market-based instruments and resource-saving management mechanisms is a prerequisite for the effective application of the proposed approach, one of which is "cleaner production" (CP).

The value of the cleaner production concept $(\mathrm{CP})$ is that it offers a methodical approach to the continuous improvement of environmental and economic efficiency.

"Cleaner Production" is a strategy of cost-effective continuous improvement of the production process in order to reduce the harmful impact on the environment.

To determine the range of tasks that contribute to the achievement of $\mathrm{CP}$ objectives, tools for CP have been developed.

$\mathrm{CP}$ provides not only an increase in revenue, but also stability (stability of the operation) of the enterprise.

The enterprise, guided by the CP concept, can receive the labeling "green" (ie "environmentally friendly") for its products.

This is an element that influences the competitiveness of domestic producers that enter the markets of developed countries.

$\mathrm{CP}$ is interfaced with international standards of environmental management systems (ISO 14001 and EMAS).

$\mathrm{CP}$ measures are classified in accordance with the costs of their implementation:

A - low-cost measures that a company can perform at its own expense;

$\mathrm{B}$ - medium-cost measures that may require small borrowed funds in addition to those that are ready to allocate to these measures the company's management;

$\mathrm{C}$ - costly measures that require significant investment.

The terms "small, medium, expensive" are relative.

The basic principles laid down in the $\mathrm{CP}$ concept:

- the principle of continuous application of this concept,

- the principle of a systematic approach in conducting CP audit and decision making,

- the principle of preventive action,

- the principle of economic efficiency of each measure proposed in terms of CP.

CP measures are directed:

- to reduce production losses of raw materials, water and energy;

- for disposal of intermediate wastes, not just waste "at the end of the pipe";

- and also for the replacement of hazardous materials used in production, less dangerous (less toxic).

In many companies in the list of low-cost priority measures, CPs fall:

- problem-solving the causes of leaks in steam and water pipelines;

- saving water by installing automatic latches on water hoses, turning off the cranes after use; 
- energy saving by switching off unnecessary lighting and other electrical appliances and much more.

There is a tendency when the leading financial markets place strict environmental requirements on companies that are present on the market.

Under the environmental factor of production, we mean the totality of acquired (purchased) permits (legal rights) for the disposal of waste, quoted on the basis of the potential of the assimilative capacity of the ecosystem in which the wastes of the production being investigated arrive.

The carried out analysis of the literature sources showed that the theoretical approaches to assessing both the damage (applied or prevented) and the assessment of the environmental and economic efficiency of enterprises, as well as the methods themselves, require further improvement [9].

The term "assimilation potential" implies the ability of the environment to take harmful waste in volumes that it can neutralize and not change its properties qualitatively at the same time.

Assimilation capacity of the ecosystem characterizes the limits of ecosystem stability to anthropogenic loads.

If we reduce the decision-making in the economy to the simplest formula, then this will be the ratio of benefits (B) and costs (C).

The main economic tool for analysis is "costs - benefits".

The ecological factor is not taken into account in modern economic analysis.

For the analysis, let us select this factor (E) and present the formula in which the condition of the project / program effectiveness is recorded, in the following form:

$$
B-C \pm E>0
$$

Depending on the environmental focus of the project / program, the environmental and economic effect may be added to the overall benefits, or, in the case of an "anti-ecological" project / program, be deducted accordingly.

The latter is the most common case, and the costs are increased.

With these comments in mind, the formula can be transformed as follows:

$$
(B+B e)-(C+C e)>0,
$$

where $B e$ is an ecological and economic effect of the project / program; $C e$ is an ecological and economic damage (additional costs) of the project / program».

J. Dickson proposed to consider "lost profits" as costs and vice versa - "avoided costs" as benefits.

If the benefits (relating to the reduction of environmental pollution) in making an investment decision are not directly measurable, then Dickson is invited to move from a cost-benefit analysis to a cost-effectiveness analysis [9].

The Gain / Cost Ratio (B / C ratio) is derived from net present value and is calculated by formula (3) as the ratio of discounted benefits to discounted costs»».

$$
B / C=\frac{\sum_{t=0}^{n} \frac{B_{1}}{(1+r)^{t}}}{\sum_{t=0}^{n} \frac{C_{1}}{(1+r)^{t}}}
$$

where $r$ is a discount coefficient; $t=\{1,2, \ldots, \mathrm{n}\}$ is the year of project implementation; $n$ is the project implementation time. 
Ecological and economic efficiency of resource saving means economically effective reduction of the company's negative impact on the environment.

To assess the environmental and economic efficiency of the enterprise, Nesterov.P.M. and Nesterov A.P. the calculation technique is proposed, which is based on the formula of the overall profitability of the enterprise:

$$
P_{\text {общ }}=\frac{\Pi_{\text {б }} \pm V}{\Phi_{о}+\Phi_{\text {об }}} \times 100,
$$

where $P_{\text {обш }}$ is the overall profitability of the enterprise; $\Pi_{\sigma}$ is the balance profit $\Phi_{o}$ is the average value of basic production assets; $\Phi_{о б}$ are average balances of standardized current assets; $\pm Y$ is damage caused or prevented (from the negative impact of the company on the environment).

In its turn

$$
\Pi_{\sigma}=E_{1}+E_{2},
$$

where $E_{1}$ is profit from sales of marketable products; $E_{2}$ is the the result of other implementation and outside the implementation activities.

The ecological and economic damage present in the formula (4) consists of 9 types of damage:

$$
y=y_{M}+y_{c}+y_{n \ni}+Y_{6 n}+y_{p}+y_{m \kappa}+Y_{m n}+Y_{H \kappa}+Y_{n c},
$$

where:

- $y_{M}, Y_{c}$ is damage in the form of metal losses as a result of additional wear and tear of metal products and machinery and from losses of inventory in warehouses, respectively;

- $y_{n э}, Y_{\varepsilon n}, Y_{p}$ is damage from additional costs for electricity, for cleaning water and air in production consumption, for repair and maintenance of production assets, respectively;

- $y_{m \kappa}, Y_{m n}$ is damage from staff turnover, from a decline in labor productivity, respectively;

- $y_{н к}$ is damage from shortage of production, quality decrease and due to poor quality of water;

- $y_{n c}$ is damage from the loss of raw materials with emissions into the atmosphere, water.

The calculation of the first term in the formula (6) seems to us problematic from the scientific and practical point of view, since:

- metal losses as a result of additional wear of metal products and mechanisms are difficult to estimate in natural units of measurement,

- to translate this value into monetary expression, you need to determine the price of this metal (the price of scrap metal or the cost of equipment subjected to wear and tear).

Similarly, there are questions in assessing the losses of raw materials with emissions into the atmosphere, and discharges into water.

The cost of raw materials, "carried away" by exhaust gases and sewage, should be taken into account at the market price of recycled waste (recyclable materials) or at the initial price of its purchase.

The calculation of the "applied or prevented economic damage" $( \pm \mathrm{Y})$ presented in the formula (4) was proposed by the Nesterovs, in analogy with the methodology for assessing prevented damage in regional environmental projects.

The Nesterovs approach, in principle, makes it possible to assess theoretically the potential for reducing damage from the negative impact of the enterprise on the environment, but because of the complexity of the calculation procedure, the methodological approach in question is of little use to management personnel of polluting enterprises. 
There is a "Temporary typical method for determining the economic efficiency of implementing environmental measures and assessing economic damage caused to the national economy by environmental pollution" (1986).

The analysis of this method allowed to draw the following conclusions:

- instructions for calculating many of the indicators included in this methodology have become obsolete because many forms of reporting referred to by the methodology have been canceled with the transition from a planned economy to a market economy;

- types of environmental measures considered in this methodology are not relevant because the assimilation capacity of natural ecosystems is exceeded in all industrial centers.

Considered in the "Temporary Typical Method ...", the measures do not reduce the overall pollution of the environment, thereby not contributing to the solution of pressing local environmental problems.

Existing methodological approaches do not implement the "polluter pays" principle introduced into the practice of the OECD countries after 1972 (after the UN Stockholm Conference).

We have proposed a different approach to the assessment of resource-saving, based on the progressive experience of solving environmental problems in developed countries.

As a basis for the calculation formula for assessing the environmental and economic efficiency of the enterprise, the formula for the profitability of output should be taken, i.e. the ratio of the profit to the expenses of the enterprise for the main activity for the reporting period.

This is the first thing that will distinguish the proposed approach from the above approach of the Nesterovs.

The second is the amount of profit that is taken into account.

The Nesterovs take into account, according to formula (5), "profit from the sale of marketable products" and "the result of other sales and non-sales activities."

We consider it expedient to exclude the second term from profit in calculating the environmental and economic efficiency of the enterprise.

Such corporate income items as (income from securities transactions, a positive exchange rate difference, income from the sale of basic and intangible assets, government subsidies, etc.) are not directly related to pollution of the natural environment.

The third thing that will distinguish our calculation formula is the allocation in the numerator of the profit from the utilization of any waste of the enterprise, which we will consider additional to the company's profit from the sale of the main products.

In the denominator, we distinguish environmental production costs separately from the total production costs for normal activities.

The proposed formula for calculating the environmental and economic efficiency (EEE) of the enterprise's operation is as follows.

$$
\text { ЭЭЭ }=\frac{\Pi_{\text {oсн }}+\Delta \Pi}{\sum_{i=1}^{n} K_{i} \cdot a_{i}+И+\sum_{j=1}^{m} K_{j} \cdot a_{j} \pm U_{n o}},
$$

where:

- $\Pi_{\text {оси }}$ is the net profit from the main product, remaining after deduction from the income from the sale of the main product of its cost, the costs of the period, taxes and mandatory payments to the state budget;

- $\Delta \Pi$ is the profit from the sale of additional products obtained in the process of waste disposal (and / or more profound processing of raw materials in the technological process);

- $\quad i=\{1,2,3, \ldots, \mathrm{n}\}$ is the serial number of the type of fixed assets and intangible assets of the enterprise by main activity, $\mathrm{n}$ is the total number of them; 
- $\quad K i$ is the discounted initial cost of the i-th type of fixed and intangible assets of the enterprise;

- $\quad a_{i}$ it the coefficient of depreciation for the i-th kind of fixed and intangible assets of the enterprise;

- $\quad И$ are current costs of production (expenses for purchasing raw materials, materials, semi-finished products, fuel, energy, wages, overheads (including maintenance costs), taxes and mandatory payments to the budget other than payments for the use of natural resources, as well as interest for loans);

- $\quad j=\{1,2,3, \ldots . \mathrm{m}\}$ - порядковый номер вида природоохранного оборудования и сооружения, $m$ - общее их количество;

- $K_{j}$ IS the discounted initial cost of the j-th type of environmental protection equipment or facilities;

- $a_{j}$ is the coefficient of depreciation for the 7th type of environmental protection equipment and facilities; $( \pm) h_{n o}$ - payments for the use of natural resources, contributions for the insurance of environmental risks and fines for violating the environmental legislation of the Russian Federation.

The proposed methodological approach to assess the environmental and economic efficiency of the enterprise can be applied when developing an action plan for improving environmental protection.

The proposed formula (7) is effective in obtaining analytical conclusions on the impact of an environmental protection measure on the overall environmental and economic efficiency of the enterprise.

Of particular interest is the mechanism such as the territorial markets for quotas for pollution of the environment (TMQP).

The mechanism of the TMQP was first successfully demonstrated in the USA to reduce emissions of sulfur oxides, it is now successfully used in many developed countries.

Territorial quotas for pollution and objectively sound environmental taxes are more flexible instruments of environmental policy than the administrative-command measures currently applied.

TMQP have an advantage over pollution taxes: provided that the OS quality is properly monitored, the "bubble principle" is implemented, according to which the total volume of emissions in the territory should not exceed the established limit (MPC). When using taxes, the total amount of emissions in the territory depends on the decisions of the companies that they adopt based on the comparison of costs (to reduce pollution) with the benefits (prevented by taxes).

The main advantage of the market for pollution quotas is the encouragement of the struggle with the general level of pollution of the territory by the forces of those companies that can achieve this in the most effective way and who then receive a reward for this.

As a result, the desired effect in the form of reducing pollution in the territory is achieved with the lowest costs for the whole society.

In addition, non-governmental organizations, territorial environmental protection agencies can participate in the TMQP to buy up quotas that they will not use, but in order to increase pressure on polluting enterprises.

Thus, the TMQP as a market mechanism for managing the quality of the OS allows to achieve such a quality OS in the territory that is desirable for the local community and which it can afford.

The " \pm " sign before Ipo in the denominator of formula (7) indicates that the company not only can pollute the environment and even exceed the established standards, but also achieve their reduction through the implementation of environmental projects. 
At the same time, enterprises have an opportunity to receive additional income from the sale of the saved quota to another enterprise interested in this territory (if the territorial markets have quotas for pollution).

Attention is also drawn to the practice of applying environmental bonds abroad, which are payments made to the relevant authorities prior to the company's performance of the undertaken environmental obligations (for example, reducing emissions, discharging pollutants, reclamating contaminated soils or purifying a natural reservoir, etc.). ).

The cost of environmental bonds is returned after the requirements are met.

This measure can be used as a mechanism to ensure compliance with regulations, as a result of environmental auditing.

To adapt these tools, as well as to improve other tools for quality management, it is necessary to assess the assimilation capacity of ecosystems.

\section{Results and discussion}

The estimated assimilation potential should be reflected in economic tools for managing the development processes of regions and industries as a factor limiting the extensive development of production.

The procedure for assessing the assimilation capacity requires complex studies.

It is necessary to establish normative indicators of quality of environmental components, levels of maximum permissible concentration (MPC) of chemicals in water, air, soil, based on the sustainability of each ecosystem, and not only sanitary and hygienic standards, since the level of critical load is different for different ecosystems.

Modern values of MPC are established on the basis of sanitary and hygienic norms that provide a safe environment for the health of the population.

From the point of view of bio-ecology for the conservation of the plant world, environmental standards (MPC) for a range of pollutants must be tightened,

At present, an overwhelming number of specialists acknowledge that the system for monitoring the quality of the natural environment, based on the differential determination of the concentration of controlled pollutants and comparing them with MPC, is ineffective.

Isolated action of individual chemicals without taking into account the real environmental situation does not reflect the true picture. The fact is that in the natural and anthropogenic ecosystems, the formation of substances that are significantly more toxic than the analyzed source compounds, as well as those that have a mutagenic, carcinogenic and allergenic effect, has occurred.

Thus, the established MPCs are of anthropocentric nature and can not provide equal protection for all objects of living nature [10].

An indispensable condition for the effective functioning of the TMQP is the availability of a modern system of instrument monitoring.

To carry out control of OS quality, optical monitoring (space photography) in combination with regular laboratory analyzes of the quality of environmental components is more preferable from the point of view of reliability.

For example, a set of equipment suitable for operation in different conditions is intended for measuring a wide range of atmospheric characteristics, as a result of which an air pollution warning system is being formed.

Based on the formula (7), a formula is proposed for calculating the ecological and economic efficiency of the whole complex (formula 8). 


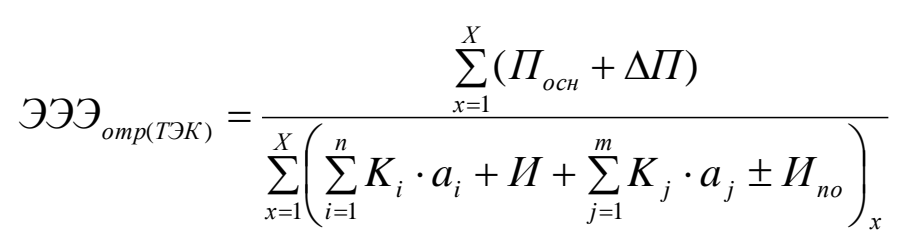

where $\mathrm{x}=\{1,2,3, \ldots, \mathrm{X}\}$ is the serial number of the enterprise in the industry database (FEC); $\mathrm{X}$ is the number of enterprises in the database of the industry being considered.

\section{Conclusion}

The study of the concepts of Eco-efficiency and Cleaner Production, widely used in developed countries, showed the applicability of the principles and tools of these concepts in the conditions of Russia.

The concept of Cleaner Production involves the use of a system of eco-efficiency indicators, which can be used to determine environmental requirements for enterprises.

The proposed methodical approach to the assessment of resource conservation involves conducting an environmentally oriented accounting of costs and revenues from waste disposal in the system of accounting for total costs and revenues of the enterprise.

The proposed approach to the assessment of resource saving is designed to implement the "polluter pays" principle, which is successfully implemented in developed countries.

The proposed approach reflects the maintenance of environmentally oriented accounting of income and expenses in enterprises.

The estimation of resource-saving according to the proposed method will allow to obtain an indicator of economic efficiency that takes into account not only its incomes and expenses for the main activity, but also economic damage to the environment as a result of production.

Environmental damage will be accounted for by the cost of pollution quotas, environmental insurance premiums, payments and penalties for violations of environmental legislation.

\section{References}

1. B. V. Tetelmin, V. A. Yazev, Environmental protection in the oil and gas sector (Publishing House "Intellect", Dolgoprudny, 2009)

2. V. V. Filatov, N. V. Kulikova, I. M. Rukina, P. Yu. Konotopov, Scientific Journal of Research Institute of ITMO - Series in Economics and Environmental Management, 2 (2014)

3. A. I. Muraviev, General theory of innovative technologies (Institute of Foreign Economic Relations, Economics and Law, St. Petersburg, 2002)

4. N. V. Voronina, Practical marketing, 10 (2013)

5. T. A. Akimova, A. P. Kuzmin, V. V. Khaskin, Ecology: nature - man - technology (Unity-date, Moscow, 2001)

6. T. N. Bessonova, Bulletin of the Ugra State University, 5 (2016)

7. S. N. Bobylev, A. Sh. Khodzhaev, Environmental economics (INFRA-M, Moscow, 2004)

8. A. E. Cherepovitsyn, Problems of Modern Economics, 4, 24 (2016) 
9. A. A. Averchenkov, A. Yu. Galenovich, G. V. Safonov, Yu. N. Fedorov, Regulation of greenhouse gas emissions as a factor to enhance Russia's competitiveness (The National Carbon Sequestration Support Organization, Moscow, 2013)

10. Key World Energy Statistics (IEA, 2014) 